\title{
IMPACTOS AMBIENTAIS SOBRE O MANGUEZAL DE SUAPE - PE.
}

\author{
Ricardo Augusto Pessôa Braga \\ Terezinha Matilde de Menezes Uchoa \\ Maria Tereza Menezes Bezerra Duarte
}

\begin{abstract}
RESUMO - A zona estuarina de Suape é formada pelos rios Massangana, Tatuoca, Ipojuca e Merepe, situando-se a cerca de $25 \mathrm{~km}$ ao sul do Recife. A implantação um porto e da infra-estrutura para um complexo industrial acarretou em obras de aterros, dragagens e represamentos, alterando a hidrologia local e modificando drasticamente a paisagem. A partir de fotografias aéreas na escala 1:30.000 obtidas nos anos de 1974 e 1988, de imagens do sensor TM do satélite Landsat 5 de 1984 e com o auxílio de carta topográfica na escala 1:25.000 de 1971, foram realizadas a fotointerpretação e a reambulação, resultando em cartas de cobertura de vegetação de mangue de 1974 e 1988, assinalando-se as intervenções físicas ocorridas neste período. Dos 2874ha de manguezal existentes em 1974, restam em 1988 2276ha, com uma perda de $21 \%$ do total. Destes 214 ha foram aterrados por aterro hidráulico ou material argiloso oriundo de outras áreas; 384ha foram alagados, em decorrêncỉa de dragagens e de inundações por represamento. Mais 27ha encontram-se em processo de degradação, devido a uma inundação temporária ocorrida, em consequência de obstrução de vazão do rio Ipojuca em sua foz, quando da construção do porto. Foram marcadas oito estaçōes nas áreas preservadas e em regeneração para caracterização da estrutura do manguezal, formado pelas espécies Rhizophora mangle L., Avicennia germinans (L.) Stearn. Avicennia shaueriana Stapf. \& Leechman, Laguncularia racemosa Gaertn.. além do Conocarpus erectus L. que ocorre perifericamente. Os bosques estudados nas áreas preservadas apresentam-se, com um bom desenvolvimento, maduros ou em amadurecimento, de acordo com os parâmetros evidenciados (densidade, área basal, altura média do bosque e diâmetro médio). Os bosques estudados nas áreas em regeneração apresentam-se bastante jovens com uma densidade elevada indicando portanto que, se estas áreas forem preservadas, tais bosques atingiräo o seu equilibrio.
\end{abstract}

Palavras-chave - manguezal, impacto ambiental.

Laboratório de Ecologia do Departamento de Biologia Geral da UFPE - Caixa Postal 7807 - Cidade Universitária, Recife-PE.

Trabalho com o auxílio do CNPq, SUDENE, IBAMA e FIPE. 


\begin{abstract}
The suape estuarine zone is formed by Massangana. Tatuoca, Ipojuca and Merepe rivers, that are located about $25 \mathrm{~km}$ Southern far from Recife. The settlement of a port and the industrial Complex structure came to cause earthwork, dredging and damming, modifying extensively the local hidrology and the scenery. Photointerpretation and reambulation were realized on the basis of aerial photographs (scale 1:30.000) taken in 1974 and 1988; images of the Landsat 5 satellite in 1984, and topographic maps (scale 1:25.000) in 1971, resulting in mangrove vegetation maps of 1974 and 1988, which clearly indicate the physical interventions during this period. In 1974 there were 2874ha of mangrove. A reduction of $21 \%$ led, in 1988 , to 2276 ha from whitch 214 ha have been landing by clay land material from other areas; 384 ha were inundated due to dredging gand diking. More than $27 \mathrm{ha}$ are in a degradation process. In order to allow the characterization of the mangrove structure, eight observation stations were settled in preserved and regenerating areas. The mangrove is formed by Rhizophora mangle L., Avicennia germinans (L.) Stearn., Avicennia schaueriana Stapf. $\xi$ Leechman., Laguncularia racemosa Gaertn. in its nucleus and Conocarpus erectus L. in the bordeline. In preserved areas, the forest of mangrove exhibit a good expansion profile in agreement with the considered parameters (density, basal area, forest height and medium diameter). The regenerating areas characterized by a high dense incipient forest what lead us to believe that if these areas will be preserved they will get the equilibrium.
\end{abstract}

Key words - magrove, environmental impact.

\title{
Introdução
}

As florestas de mangue constituem um aspecto muito importante nos litorais tropicais de todo o mundo. Sua localização é restrita à faixa entre marés, reentrâncias da costa, contornos de baías e estuários, funcionando como ponto de ligação entre os ambientes marinhos e terrestres.

Os manguezais são encontrados em latitudes entre os trópicos de Câncer e Capricórnio, tanto nas Américas, como na África e Oceania. Certos fenômenos oceanográficos podem modificar as condições típicas desta zona intertropical, e os bosques de mangue podem vir a não se desenvolver dentro destes limites latitudinais (SCHAEFFER-NOVELLI, 1982).

McGILL, 1958 (in WALSH, 1974), estima que entre 60 e $75 \%$ das costas entre $25^{\circ} \mathrm{N}$ e $25^{\circ} \mathrm{S}$ estão cobertas por manguezais. No Brasil os manguezais ocorrem desde o Amapá - $02^{\circ}$ latitude Norte, até o litoral de Santa Catarina, na foz do rio Ararangá - cerca de $29^{\circ}$ latitude Sul (LAMBERTI, 1969).

As áreas de manguezal são representativas de zonas de elevada produtividade biológica, uma vez que pela natureza de seus componentes, são encontrados nestes ecossistemas representantes de todos os elos da cadeia alimentar. Os corpos de água, baías, lagunas e estuários, quando margeados por bosques de mangue recebem a importante contribuição dos compostos húmicos, com destacada função no condicionamento biológico, favorecendo sobremaneira sua alta produção (SCHAEFFER-NOVELLI, 1982). 
Segundo WALSH, 1974, os manguezais desenvolvem-se em maior grau, onde evidenciam-se estas cinco condições: 1 - temperaturas quentes (tropicais); 2 - substratos aluviais, onde predominam lodos finos ricos em matéria orgânica; 3 - costas livres de fortes ondas, que impedem o assentamento das sementes; 4 - águas salinas, entre 5 e 30\% ; 5 - grandes amplitudes de marés e pequena declividade da costa, garantindo grande penetração da maré salina.

As árvores do manguezal alcançam até $45-50 \mathrm{~m}$ de altura em ambientes bastante favoráveis, próximos do Equador, onde existe disponibilidade de nutrientes, grandes amplitudes de marés, e temperaturas altas e constantes. Por outro lado em seus limites latitudinais, onde as temperaturas são mais baixas e os bosques sofrem o impacto periódico de geadas, a altura da copa não excede os 2m (CINTRÓN $\xi$ SCHAEFFER-NOVELLI, 1983).

Comparando-se a outros ecossistemas com condicionamentos físicos menos rigorosos, os manguezais apresentam um baixo número de espécies botânicas.

No novo mundo as espécies que compõe o mangue estão distribuídas entre os gêneros: Rhizophora (3); Avicennia (4); Laguncularia (1); Conocarpus (1); e Pelliciera (1), no total de 10 espécies. No Brasil ocorrem os gêneros Rhizophora, Avicennia, Laguncularia e Conocarpus (CINTRÓN $\xi$ SCHAEFFER-NOVELLI, 1983).

Os autores indicam a região Norte do Brasil com um maior número de espécies do gênero Rhizophora ( $R$. mangle L., $R$. harrisonii Leechman e $R$. racemosa G.F.Meyer).

$R$. racemosa e $R$. harrisonii distribuem-se apenas do Caribe até o litoral do Pará (PRANCE et al., 1975). As três espécies do gênero Rhizophora são indicadas para o Golfão Maranhense, no estuário do rio Preguiças, numa latitude de $2^{\circ} 40^{\prime}$ 'S (SANTOS, 1986).

As espécies $R$. mangle L., Avicennia schaueriana Stapf. $\xi$ Leechman, Avicennia germinans (L.) Stearn., Laguncularia racemosa Gaertn. e Conocarpus erectus L. ocorrem, praticamente ao longo de todo litoral brasileiro, até o seu limite de $29^{\circ} \mathrm{Sul}$ em Santa Catarina, com exceção de $A$. germinans que tem o seu limite referido no Espírito Santo (aproximadamente $23^{\circ} \mathrm{Sul}$ latitude) por JIMENEZ e LUGO, 1985.

DAVIS, 1940 (in ODUM, 1959), aponta os manguezais como importantes não só para ampliar costas e formar ilhas, mas para proteger aquelas da excessiva erosão que, de outro modo, se produziria com as violentas chuvas tropicais.

No Brasil, embora não se tenha dados precisos, calcula-se que a área de manguezal atinja cerca de $25.000 \mathrm{~km}^{2}$, distribuídos ao longo do litoral, desde o Cabo Orange, no Amapá, até Araranguá, em Santa Catarina (LACERDA, 1984).

O Estado de Pernambuco, apesar de possuir um litoral de pequena extensão, com apenas $187 \mathrm{~km}$, apresenta uma concentração de manguezais bastante significativa devido à sua posição geográfica e por apresentar altitudes bas- 
tante reduzidas, que favorece o desenvolvimento da vegetaçáo de mangue. As áreas mais representativas se registram no litoral Norte, onde o maciço cristalino, mais se afasta do oceano e, onde os depósitos do Grupo Barreiras são bastante trabalhados pela drenagem (LIMA, 1970).

As treze sonas estuarinas de Pernambuco (Figura 1) vêm sofrendo um processo contínuo de degradação. Em alguns casos, a destruição já é quase completa, como no estuário do rio Beberibe (BRAGA, 1986a). Em outros casos, como na zona estuarina de Barra de Sirinhaém, a degradação é de menor intensidade (BRAGA, 1986b).

\section{Área em Estudo}

O complexo estuarino de Suape está localizado em uma região que abrange trechos dos municípios do Cabo e Ipojuca, no Estado de Pernambuco. Situado na zona fisiográfica do litoral compreendido entre os paralelos de $8^{\circ} 20^{\prime} 00^{\prime \prime}$ de latitude Norte e $8^{\circ} 29^{\prime} 00^{\prime \prime}$ de latitude Sul e entre os meridianos $34^{\circ} 56^{\prime} 30^{\prime \prime}$ " Este e $35^{\circ} 03^{\prime} 00^{\prime \prime}$ Oeste. É formada pelo estuário dos rios Massangana, Tatuoca, Ipojuca e Merepe (Figura 2).

Os solos dos manguezais de Pernambuco são classificados como "Solos Indiscriminados de Mangues textura indiscriminada" (JACOMINE et al., 1973), os quais de uma maneira geral não possuem nítida diferenciação de horizontes, exceto nas áreas marginais, onde verifica-se o desenvolvimento de um horizonte A1. Apresentando textura variável, desde argilosa até arenosa.

$\mathrm{Na}$ área em estudo, a precipitação variou de 1800 a $3850 \mathrm{~mm}$ por ano (nos últimos cinco anos) e atingiu $2408,8 \mathrm{~mm}$ em 1988, apresentando-se favorável ao desenvolvimento dos manguezais.

A temperatura média na área em estudo permaneceu entre 22,8 e $27,8^{\circ} \mathrm{C}$ (nos últimos cinco anos), sendo a mínima de $19,7^{\circ} \mathrm{C}$ e a máxima de $31,8^{\circ} \mathrm{C}$ para 1988, caracterizando um clima de temperaturas quentes, condição necessária para o bom desenvolvimento dos bosques de mangue.

Os dados de precipitação e temperatura para a área em estudo foram fornecidos pelo Instituto Nacional de Meteorologia - Ministério da Agricultura, 3을 Distrito de Meteorologia, Recife-PE.

Os dados acima caracterizam o clima do tipo Ams' da classificação de Köppen, que caracteriza o litoral de Pernambuco de $7^{\circ}$ a $10^{\circ} \mathrm{S}$, com a temperatura do mês mais frio superior a $18^{\circ} \mathrm{C}$, e a precipitação do mês mais seco não ultrapassando os $60 \mathrm{~mm}$ (SERRA, 1978). $\mathrm{O}$ índice xerotérmico (número de dias biologicamente secos) fica entre o e 40 , com 1 a 2 meses de período seco caracterizando o clima xeroquimênico, segundo a classificação de GAUSSEN (BAGNOULS $\xi$ GAUSSEN, 1963).

\section{Metodologia}

a) Cartografia.

No processo da avaliação dos impactos ambientais de zonas estuarinas, é de fundamental importância a análise comparativa temporal utilizando sensores 
remotos.

Nesta área específica foram analisadas basicamente os recobrimentos aerofotogramétricos na escala 1:30.000 realizados em 1974 e 1988. Foram utilizados também outros recursos que embasaram a realização desse estudo, resultando na análise do comportamento do meio físico ambiental, dando ênfase à vegetação do manguesal, em relação à sua evolução e às suas alterações, principalmente ocasionadas pela ação do homem.

Além da interpretação dos produtos de sensores e da avaliação das mudanças ocorridas nas diferentes fases temporais, as informaçẽos foram complementadas e comparadas com dados obtidos no campo através de reambulação.

$\mathrm{Na}$ metodologia adotada foram obedecidas as seguintes etapas:

1 - Coleta de material - esta consistiu na obtenção do material existente tais como:

. carta topográfica da SUDENE do ano de 1971;

. ortofotocartas na escala 1:10.000 da FIDEM, elaboradas a partir de fotografias aéreas de 1974;

. fotografias aéreas na escala 1:30.000 obtidas nos anos de 1974, 1984 (parte da área) e 1988;

. imagens do sensor TM do satélite Landsat 5 de 28 de julho de 1984;

- mapeamento da cobertura vegetal na escala 1:10.000 realizado por técnicos da FIDEM e fotografias panorâmicas tiradas de avião SESNA em fevereiro de 1988.

2 - Análise do mapeamento existente da cobertura vegetal da Região Metropolitana do Recife - RMR, na escala 1:10.000 e a fotointerpretação das fotografias aéreas de 1974, registrando e detalhando algumas informações, adquando às necessidades do trabalho.

3 - redução das informações do mapeamento da escala 1:10.000 para a escala 1:25.000 utilizando o Pantógrafo de Precisão A.OTT da Kempten.

4 - Transferência das informações para o mapa base elaborado através de compilação da carta topográfica da SUDENE na escala 1:25.000, utilizando mesa de luz.

5 - Fotointerpretação através do exame estereoscópico das fotografias a partir dos vôos de 1974, de 1984 e de 1988. No processo de delimitação das manchas homogêneas sobre as fotografias, foram analisadas as características do manto vegetal que constituem aspectos importantes na determinação das classes de vegetação, tais como: porte, predominância, forma, textura fotográfica, densidade, tonalidade, além de outros fatores como o relevo e a hidrografia, que permitem também definir o tipo de vegetação.

6 - Reambulação - teve como finalidade a verificação "in loco" das dúvidas assinaladas nas fotografias aéreas durante a realização da fotointerpretação, ao mesmo tempo em que se buscou atualizar as informações. Esta etapa é de suma importância porque confirma e expõe detalhes que não puderam ser devidamente observados através da fotointerpretação realizada em gabinete.

7 - Transferência das informações delimitadas nas fotografias aéreas para o mapa base na escala 1:25.000. Nesta operação foi utilizado o instrumento óp- 
tıco Zoom Transfer Scope (ZTS). Estas informações plotadas em cópias heliográficas receberam posteriormente tratamento de arte final.

8 - Análise comparativa temporal - após análise das informações obtidas em gabinete e campo foi efetuada uma avaliação das alterações ocorridas principalmente no manguezal, registrando assim as transformações na área em apreço no período compreendido entre os anos de 1974 e 1988. Nesta análise comparativa foram registrados os diferentes estágios do manguezal: mangue preservado, mangue degradado por alagamento, mangue degradado por aterro, mangue em degradação, mangue em recuperação.

9 - Elaboração da carta das intervenções através do processo automático de digitalização, a partir da carta analógica de intervenções, utilizando o sistema gráfico interativo GRADIS-2.000. Obtendo-se como resultado o cálculo e percentual das alterações ocorridas nas áreas do manguezal, como também uma saída gráfica das mesmas em ploten Calcomp - 1039. Esta etapa foi desenvolvida pela equipe de geoprocessamento da FIDEM."

b) Vegetação

Para a caracterização da estrutura dos bosques de mangue seguiu-se a metodologia de SCHAEFFER-NOVELLI $\xi$ CINTRÓN, 1986, os quais afirmam que a descrição estrutural de um bosque nos dá uma idéia do grau de desenvolvimento, além de permitir a identificação e a delimitação de bosques com propriedades semelhantes, permitindo realizar comparações entre áreas diferentes.

Escolheu-se oito estações de amostragem, orientadas por fotografias aéreas na escala 1:30.000, realizadas pela FAB em março de 1988. Cada estação apresenta uma área de 25,50 ou $100 \mathrm{~m}^{2}$, em função da estrutura apresentada, sendo evidenciadas sua posição na Figura 2.

Em cada estação identificou-se as espécies de vegetais superiores, no campo e em herbários (IPA, UFPE e PEUFR); foram mensuradas a altura (h), circunferência à altura do peito (CAP), anotado o estado de conservação da área e contado o número de plântulas. Com estes dados foi delineada a estrutura da vegetação de mangue, informando sobre a composição específica, diâmetro à altura do peito (DAP), área basal (g), densidade (número de indivíduos/0,1ha), altura média do bosque, diâmetro médio (DAP) e índice de complexidade dos bosques.

\section{Resultados}

a) Cartografia

Após as diversas fases de estudo e utilizando informações de diferentes épocas, foram elaborados os produtos relacionados:

. carta planimétrica nas escalas de 1:25.000 e 1:50.000, evidenciando a distribuição do manguezal na região de Suape, a partir das fotografias aéreas de 1974;

. carta de intervenções na zona estuarina de Suape, a partir do recobrimento aerofotogramétrico de 1988, nas escalas de 1:25.000 e 1:50.000, evidenciando 
Impactos ambientais sobre o manguezal...

as áreas de mangues ainda preservados, em degradação. degradados e em recuperação;

. carta digital de intervenções na zona estuarina de Suape nas escalas 1:25.000 e 1:50.000 - 1988;

. carta de ocupação e uso do solo na região de Suape ( $8^{\circ} 20^{\prime} 00^{\prime \prime} \mathrm{N}$ e $8^{\circ} 29^{\prime} 00^{\prime \prime} \mathrm{S}$; $34^{\circ} 56^{\prime} 30^{\prime \prime} \mathrm{E}$ e $35^{\circ} 03^{\prime} 00^{\prime \prime} \mathrm{W}$ ) em 1974, na escala de 1:25.000.

A partir do levantamento cartográfico realizado constatou-se que em 1974, a cobertura da vegetação de mangue no complexo estuarino de Suape era de 2.874ha. Após quatorze anos, em 1988, 598ha de mangues haviam sido destruídos e mais 27 ha encontram-se em processo avançado de degradação. Estas mudanças decorrem das obras de implantação do complexo industrial e portuário de Suape, com aterros, dragagens e inundações das áreas anteriormente preservadas.

A abordagem cartográfica, todavia, evidenciou uma área de 124ha, que em 1974 não apresentava cobertura vegetal e que em 1988, evidenciou vegetação de mangue em recomposição.

De acordo com o mapa da situação atual do manguezal em 1988 (Figura 3), 2.249ha estão ainda preservados, $27 \mathrm{ha}$ em degradação e $124 \mathrm{ha}$ em recuperação. Dos 598ha de manguezal degradado, 384ha encontram-se destruídos por alagamento e 213ha por aterramento.

Considerando-se apenas a área de jurisdição do complexo industrial e portuário, dos 1.005 ha de mangue existentes dentro dos seus limites, $60 \%$ já estão degradados. Estas alterações ocorreram principalmente no manguezal do rio Tatuoca e parcialmente nos rios Massangana e Ipojuca.

\section{b)Vegetação}

O manguezal do complexo estuarino de Suape, apresenta cinco espécies típicas, básicas: Rhizophora mangle L., Laguncularia racemosa Gaertn., Avicennia germinans (L.) Stearn., Avicennia schaueriana Stapf. $\xi$ Leechman e Conocarpus erectus L., entre outras espécies que ocorrem marginalmente e são facultativas, que são apresentadas na Tabela 1.

A Figura 4 apresenta a composição percentual de espécies em cada estação, evidenciando-se que a espécie dominante pode ser a $R$. mangle ou $L$. racemosa, isto de acordo com as condições locais de sedimentologia e de encharcamento por água da maré.

Nas estações I e VI a $R$. mangle é exclusiva; na estação II a $R$.mangle domina com $87,5 \%$ dos indivíduos. Nas demais estações a espécie dominante é a $L$. racemosa, com percentuais de 74,5\% (estação IV) e 95,24\% (estação III).

A A. germinans e A. schaueriana apresentam baixos percentuais de composição em espécies.

O Conocarpus erectus ocorre perifericamente às áreas, não constando nas parcelas amostradas. Em menor proporção ocorre perifericamente a Dalbergia ecastophyllum (L.) Taub., como também espécies de porte menor: Sporobolus 
virginicus (L.) Kunth., Cyperus sp., Cyperus aff. ligularis L., Eleocharis sp., Eleocharis caribaea (Rottb.) Blak. e Acrostichum aureum L.

A Figura 5 evidencia para cada estação de amostragem a participação em área basal de cada espécie ocorrente. Esta informação é particularmente interessante, nos casos em que, embora a densidade de uma espécie seja alta, a sua participação na biomassa total é pequena, em função de seu pequeno diâmetro à altura do peito (DAP) e consequentemente menor área basal. É o que ocorre acentuadamente nas estações III e IV. Na estação III, os $95 \%$ de indivíduos de $L$. racemosa representam apenas $40 \%$ de área basal total, uma vez que a $A$. schaueriana apresenta porte bem maior e DAP superior. Na estação IV repetese o fenômeno, os $75 \%$ de indivíduos de $L$. racemosa correspondem a $43 \%$ em área basal, enquanto que os $25,5 \%$ de $A$. germinans correspondem a $57 \%$ do total de área basal.

Na Tabela 2 temos os valores de densidade, frequência em função do DAP, área basal, altura média do bosque, DAP e índice de complexidade para as oito estações.

A estação I, localizada à margem esquerda da foz do rio Ipojuca, onde o bosque apresenta altura média de $17,8 \mathrm{~m}$, composição em espécie com $100 \%$ de $R$. mangle, área basal total de $4,812 \mathrm{~m}^{2} / 0$, 1ha, sendo $97,7 \%$ desta na faixa de DAP $\geqslant 10 \mathrm{~cm}$. A densidade de indivíduos (n\% $/ 0,1 \mathrm{ha})$ é de 170 , e a densidade de troncos (no/0,1ha) é de 180, nestas $87,5 \%$ e $88,89 \%$ destes indivíduos e troncos, respectivamente, estão na faixa de DAP $\geqslant 10 \mathrm{~cm}$, podendo-se então, considerar este um bosque maduro, tendo $\mathrm{DAP}=18,98 \mathrm{~cm}$ e índice de complexidade $=14,53$.

Foram constatadas na área, a ocorrência de muitas plântulas de $R$. mangle e raras de $A$. germinans, evidenciando a capacidade de recomposição da área. O estado de conservação é bom.

A estação II, localizada à margem direita da foz do rio Ipojuca, onde o hosque aprẹcenta altụra m仓́dia de $13,8 \mathrm{~m}$, composição em espécie com $87,5 \%$ de $R$. mangle e $12,5 \%$ de A. schaueriana, área basal total de $2,485 \mathrm{~m}^{2} / 0,1$ ha, sendo $92 \%$ desta na faixa de DAP $\geqslant 10 \mathrm{~cm}$. A densidade de indivíduos (no/0, 1ha) é de 160 , e a densidade de troncos (no/0, 1ha) é de 170 , nestas $81,25 \%$ e $76,47 \%$ destes indivíduos e troncos, respectivamente, estão na faixa de DAP $\geqslant$ $10 \mathrm{~cm}$, podendo-se então, considerar este, um bosque maduro, tendo DAP = $13,64 \mathrm{~cm}$ e índice de complexidade $=11,0$.

Constatou-se raras plântulas na área, de $R$. mangle e $L$. racemosa. Existência de corte seletivo de árvores, em pequena intensidade.

A estação III, localizada em Celeiro de dentro, a cerca de $300 \mathrm{~m}$ da margem direita da foz do estuário do rio Ipojuca, onde o bosque apresenta altura média de $9 \mathrm{~m}$, composição em espécie com $59,96 \%$ de $A$. schaueriana e 40,01\% de $L$. racemosa, área basal total de $1.466 \mathrm{~m}^{2} / 0,1$ ha, sendo $65,89 \%$ na faixa de DAP $\geqslant 10 \mathrm{~cm}$, e nesta faixa $90,99 \%$ corresponde a área basal de um único indivíduo de A. schaueriana. A densidade de indivíduos (no/0,1ha) é de 210 , e a densidade de troncos (no/0,1ha) é de 250 , nestas $61,9 \%$ e $51 \%$ destes indivíduos e troncos, respectivamente, estão na faixa de $5 \mathrm{~cm} \leqslant$ DAP , $10 \mathrm{~cm}$, po- 
dendo-se então, considerar este, um bosque em amadurecimento, tendo DAP = $6,82 \mathrm{~cm}$ e índice de complexidade $=11,81$.

Não constatou-se a ocorrência de plântulas na área. .Evidenciou-se troncos cortados, e rebrotos nestes.

A estação IV, localizada em uma ilha no rio Ipojuca, próxima à Usina Salgado, em Nossa Senhora do Ó (recebe o nome local de Ponto do Cavalo), onde o bosque apresenta altura média de $13,4 \mathrm{~m}$, composição em espécie com $74,5 \%$ de $L$. racemosa e $25,5 \%$ de $A$. germinans, área basal total de $2,433 \mathrm{~m}^{2} / 0,1$ ha, sendo $84,3 \%$ desta na faixa de DAP $\geqslant 10 \mathrm{~cm}$. A densidade de indivíduos (n\%/0,1ha) é de 120 , e a densidade de troncos $(\mathrm{n} \% / 0,1$ ha) é de 140 , nestas cerca de $32 \%$ encontra-se com DAP $\geqslant 10 \mathrm{~cm}$ e cerca de $48 \%$ com DAP $\leqslant 5 \mathrm{~cm}$, podendo-se então, considerar este, um bosque ainda em amadurecimento, tendo DAP $=10,16 \mathrm{~cm}$ e índice de complexidade $=33,71$.

Não verificou-se ocorrência de plântula na área.

A estação $\mathrm{V}$, localizada à margem direita, no segmento médio do estuário do rio Merepe, onde o bosque apresenta altura média de $8 \mathrm{~m}$, composição em espécie com $94,5 \%$ de $L$. racemosa e $5,5 \%$ de A. schaueriana, área basal total de $1,8003 \mathrm{~m}^{2} / 0,1$ ha, sendo $60,9 \%$ na faixa de $2,5 \mathrm{~cm} \leqslant$ DAP $\leqslant 5 \mathrm{~cm}$, e $39,1 \%$ entre 5 e $10 \mathrm{~cm}$. A densidade de indivíduos (no/0,1ha) é de 1120 , e a densidade de troncos $(\mathrm{n} \% / 0,1$ ha) é de 1140, nas mesmas faixas anteriormente mencionadas, podendo-se então, considerar este, um bosque em amadurecimento, onde o processo de seleção natural ainda não se faz sentir, tendo DAP $=4,52 \mathrm{~cm}$ e índice de complexidade $=39,6$.

Foi constatado muitos troncos cortados, muitos rebrotos e ocorrência de plântulas de L. racemosa.

A estação VI, localizada à margem esquerda, no segmento médio do estuário do rio Merepe (antes do porto de Celeiro), onde o bosque apresenta altura média de $15 \mathrm{~m}$, composição em espécie com $100 \%$ de $R$. mangle, área basal total de $2,395 \mathrm{~m}^{2} / 0,1$ ha, sendo $75 \%$ desta na faixa de DAP $\geqslant 10 \mathrm{~cm}$. A densidade de indivíduos (n\%/0,1 ha) é de 180, e a densidade de troncos (n\%/0,1ha) é de 200 , sendo de $50 \%$ destes na faixa de $5 \mathrm{~cm}<$ DAP $<10 \mathrm{~cm}$ e $40 \%$ com DAP $>$ $10 \mathrm{~cm}$ podendo-se então, considerar este um bosque ainda em amadurecimento, tendo DAP $=4,5 \mathrm{~cm}$ e índice de complexidade $=6,49$.

Foram constatadas raras plântulas de $R$. mangle.

A estação VII localizada na fazenda Merepe, próxima à mata do Muro Alto, correspondendo a uma área de regeneração, onde o bosque apresenta altura média de $6,0 \mathrm{~m}$, composição em espécie com $99,1 \%$ de $L$. racemosa e $0,9 \%$ de $R$. mangle, área basal de $1,543 \mathrm{~m}^{2} / 0,1$ ha, sendo $57,6 \%$ desta, na faixa de DAP $\leqslant 2,5 \mathrm{~cm}, 26,7 \%$ com $2,5 \mathrm{~cm}<$ DAP $\leqslant 10 \mathrm{~cm}$. A densidade de indivíduos (no/0,1 ha) é de 6480, e a densidade de troncos (no/0,1ha) de 6860, ocorrendo estes predominantemente na faixa de DAP $\leqslant 2,5 \mathrm{~cm}$ podendo-se então, considerar este um bosque jovem, onde o processo de seleção natural ainda não é marcante, tendo DAP $=1,74 \mathrm{~cm}$ e índice de complexidade $=124,86$.

Verificada alta incidência de plântulas de L. racemosa, indicando a ativi- 
dade de regeneração da área.

A estação VIII localizada em frente ao viveiro, conhecida como Luís de Bés, é uma faixa estreira de manguezal, correspondendo a uma área de regeneração, onde o bosque apresenta altura média de $8,4 \mathrm{~m}$, composição em espécie com $100 \%$ de L.racemosa, área basal total de $1,403 \mathrm{~m}^{2} / 0,1$ ha, sendo $66 \%$ na faixa de DAP $\leqslant 2,5 \mathrm{~cm}, 23 \%$ com $2,5 \mathrm{~cm}<$ DAP $\leqslant 5 \mathrm{~cm}$, e só $11 \% \mathrm{com} 5 \mathrm{~cm}$ $<$ DAP $<10 \mathrm{~cm}$. A densidade de indivíduos (no/0,1ha) é de 5440, sendo cerca de $92 \%$ destes na faixa de DAP $\leqslant 2,5 \mathrm{~cm}$, podendo-se, então, considerar este um bosque jovem, com DAP $=1,85 \mathrm{~cm}$ e índice de complexidade $=123,25$.

Foi constatada a ocorrência de muitas plântulas, confirmando junto com a densidade, ser esta uma área de regeneração. Paralelamente, constatou-se alta incidência de troncos cortados, indicando ser uma área com corte intenso de madeira.

$\mathrm{O}$ índice de complexidade apresentou-se baixo para as estações I a VI, comparando-se os seus valores com os do trabalho de POOL, SNEDAKER $\xi$ LUGO, 1977, que indicam a faixa de 49,7 - 73,2 como um alto índice, devido às áreas basais elevadas. Nas estações VII e VIII o índice de complexidade apresentou-se muito alto, devido às densidades elevadas.

\section{Conclusōes}

Em função dos resultados apresentados, conclui-se que:

- A zona estuarina de Suape tem sofrido, particularmente, nos últimos 14 anos, um processo de degradação acentuado. As maiores destruições foram provocadas pelas obras de aterro, dragagens e represamentos, decorrentes da implantação do complexo industrial e portuário de Suape.

- dos 2.874 hectares de manguezal existentes em 1974, $22 \%$ foram degradados, o que equivale a 625 hectares. Destes, 598 hectares foram totalmente destruídos e 27 hectares encontram-se em estágio avançado de comprometimento.

- Considerando apenas a área de jurisdição do complexo industrial e portuário de Suape, dos 1005 hectares de mangue existentes dentro de seus limites, $60 \%$ já estão degradados. Estas alterações ocorrem principalmente no manguezal do rio Tatuoca e parcialmente nos rios Massangana e Ipojuca.

- Em contrapartida, no manguezal do rio Merepe, uma área periférica de 124 hectares situada próxima a Nossa Senhora do Ó, fora dos limites do "Projeto de Suape", encontra-se em processo de regeneração. A mesma área em 1974 encontrava-se desmatada.

- As espécies típicas ocorrentes no manguezal de Suape são: Rhizophora mangle L., Avicennia germinans (L.) Stearn., Avicennia schaueriana Stapf. $\xi$ leechman. Laguncularia racemosa Gaertn. e Conocarpus erectus L.

- Os bosques estudados nas áreas preservadas apresentam-se com um bom desenvolvimento, maduros ou em amadurecimento, de acordo com os 
parâmetros evidenciados.

- Os bosques estudados nas áreas em regeneração apresentam-se bastante jovens, com uma densidade elevada, indicando portanto que se estas áreas forem preservadas, os bosques atingirão o seu equilibrio.

\section{Referências Bibliográficas}

1 - ANDRADE-LIMA, A. 1970. Recursos Vegetais de Pernambuco. IN: Cadernos do Conselho de Desenvolvimento de Pernambuco. CONDEPE. Recife. p. 45-50.

2 - BAGNOULS, F $\xi$ GAUSSEN, H. 1963. Os climas biológicos e sua classificação. Boletim Geográfico, Rio de Janeiro, 22(176): 545-566.

3 - BRAGA, R. A. P. 1986a. Caracterização do rio Beberibe e propostas de recomposição. In: Estudos Nordestinos do Meio Ambiente. Recife. Ed. Massangana. p. 161-207.

4 - - 1986b. Caracterização Preliminar da Zona Estuarina de Sirinhaém. Recife, CPRH. 62 p.

5 - CINTRÓN, G. $\xi$ SCHAEFFER-NOVELLI, Y. 1983. Introdución a la ecologia del manglar. Montevideo, UNESCO/ROSTLAC. 109 p.

6 - CONDEPE $\xi$ CPRH, 1970. Estudo para controle ambiental nas áreas estuarinas de Pernambuco - Canal de Santa Cruz. Recife.

7 - FIDEM. 1979. Mapeamento temático da cobertura vegetal da RMR; relatório do Município de Jaboatão. Recife, p. 7-9.

8 - JACOMINE, P. K. T.; CAVALCANTI, Q. C, BURGOS, N.; PESSOA, S. C. P.; SILVEIRA, C. O. da S. 1973. Levantamento exploratório - reconhecimento de solos do Estado de Pernambuco. Recife, Divisão de Pesquisa Pedológica. v.1. (Boletim Técnico, 26. Série Pedológica, 14).

9 - JIMENEZ, J. A. $\xi$ LUGO, A. E. 1985. Avicennia germinans (L) L. mangrove, Avicenniaceae verbena family. Rio Piedras, Institute of Tropical Forestry. 6p. (Silvics Manual, 3).

10 - LACERDA, L. D. 1984. Manguezais - florestas de beira-mar. In: Ciência Hoje, 3(13):63-70.

11 - LAMBERTI, A. 1969. Contribuição da ecologia das plantas do manguezal de Itanhaém. Boletim da Faculdade de Filosofia, Ciências e Letras da USP. Botanica, São Paule, 23(317): 1-217.

12 - ODUM, E. P. 1959. Fundamentos da ecologia. 2.ed. Lisboa. Fundação Calouste Gulbenkian. 320p.

13 - POOL, D. J.: SNEDAKER, S. C.: LUGO. A. E. 1977. Structure of mangrove forests in Florida. Puerto Rico, Mexico and Costa Rica. Biotropica, Washington. 9(3):195-212.

14 - PRANCE. G. T.; SILVA, M.F. da; ALBUQUERQUE, B.W.; ARAÚJO, I. de J. da S.; CARREIRA. L. M. M. BRAGA. M. M. N.; MACEDO. M.: CONCEIÇAO. P. N. da: LISBOA. P. L. B.: BRAGA. P. J.: LISBOA, R. C. L.: VILHENA. R. C. Q. 1975. Revisão Taxonômica das espécies amazônicas da Rhizophoraceae. Acta Amazônica, Manaus, 5(1):5-22.

15 - SANTOS. M. C. F. V. dos. 1986. Consideraçöes sobre a ocorrência de Rhizophora harrisonii Leechman e Rhizophora racemosa G. F. W. Meyer, no litoral do Estado do Maranhão, Brasil. Boletim do Laboratório de Hidrobiologia, São Luís. 7:71-91.

16 - SCHAEFFER-NOVELLI, Y. 1982. Importância do manguezal e sua comunidades. São Paulo, Instituto Oceanográfico. n.p. 
17 - CINTRÓN, G. 1986. Guia para estudo das áreas de manguezal; estrutura, função e flora. São Paulo, s. ed. 150 p.

18 - SERRA, A. 1978. Climatologia do Brasil - 15. Boletim Geográfico, Rio de Janeiro, 36(257):104-194.

19 - WALSH, G. E. 1974. Mangroves: a review. London, Academic Press. 174 p. 


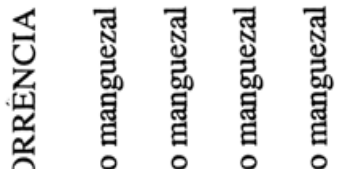

仓ூ 岕 总

究

맘

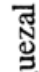

苜

E

ฐี

范<smiles>CC(C)=O</smiles>

을

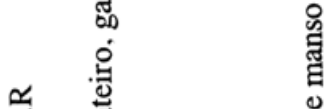

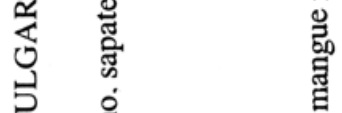

氶

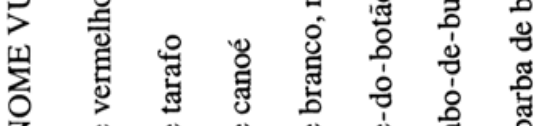

๖

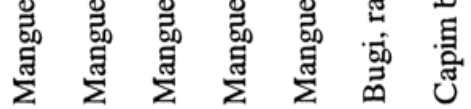

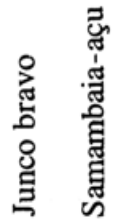

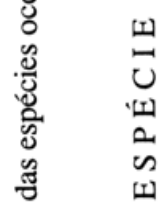

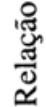

䄸

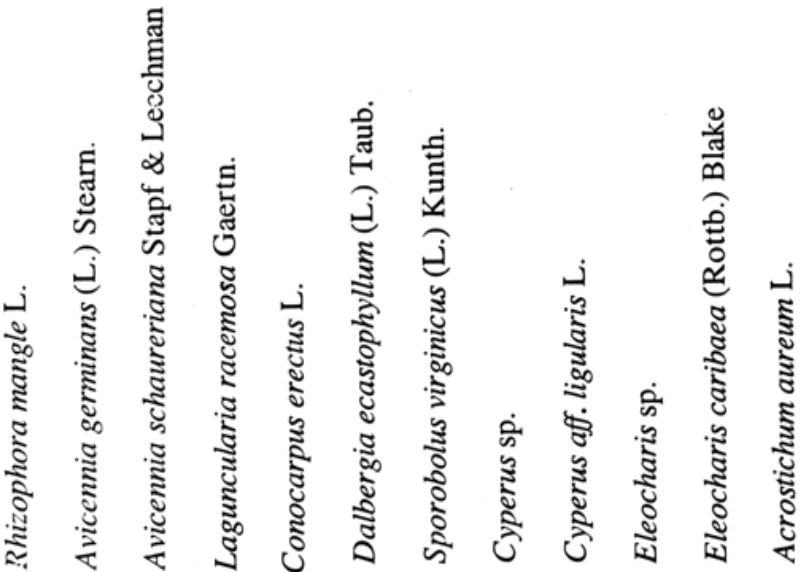

ভ

嵌 


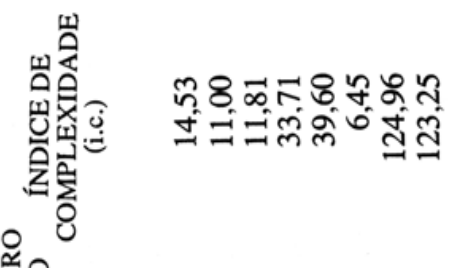

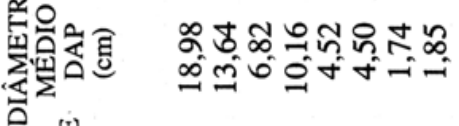

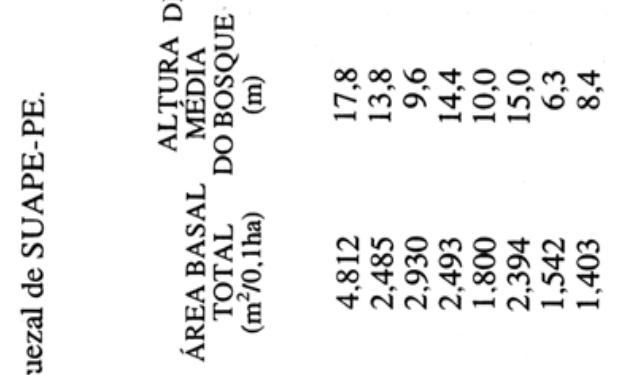

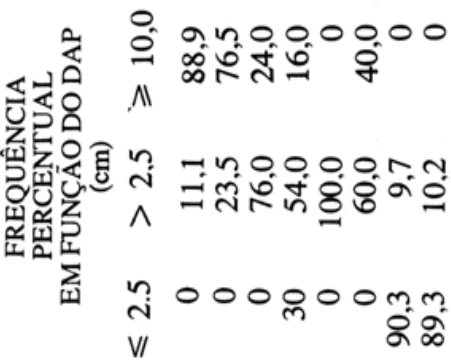

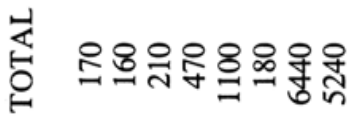

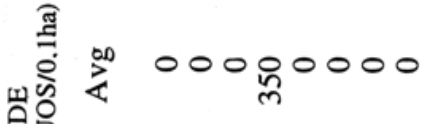

옹

帘会

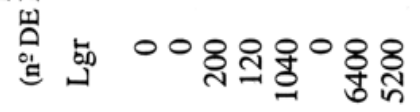

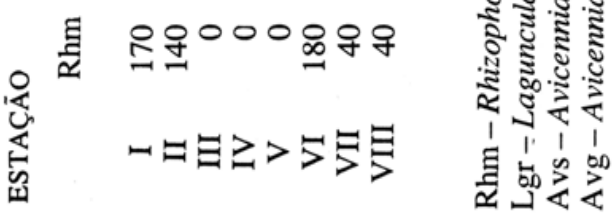




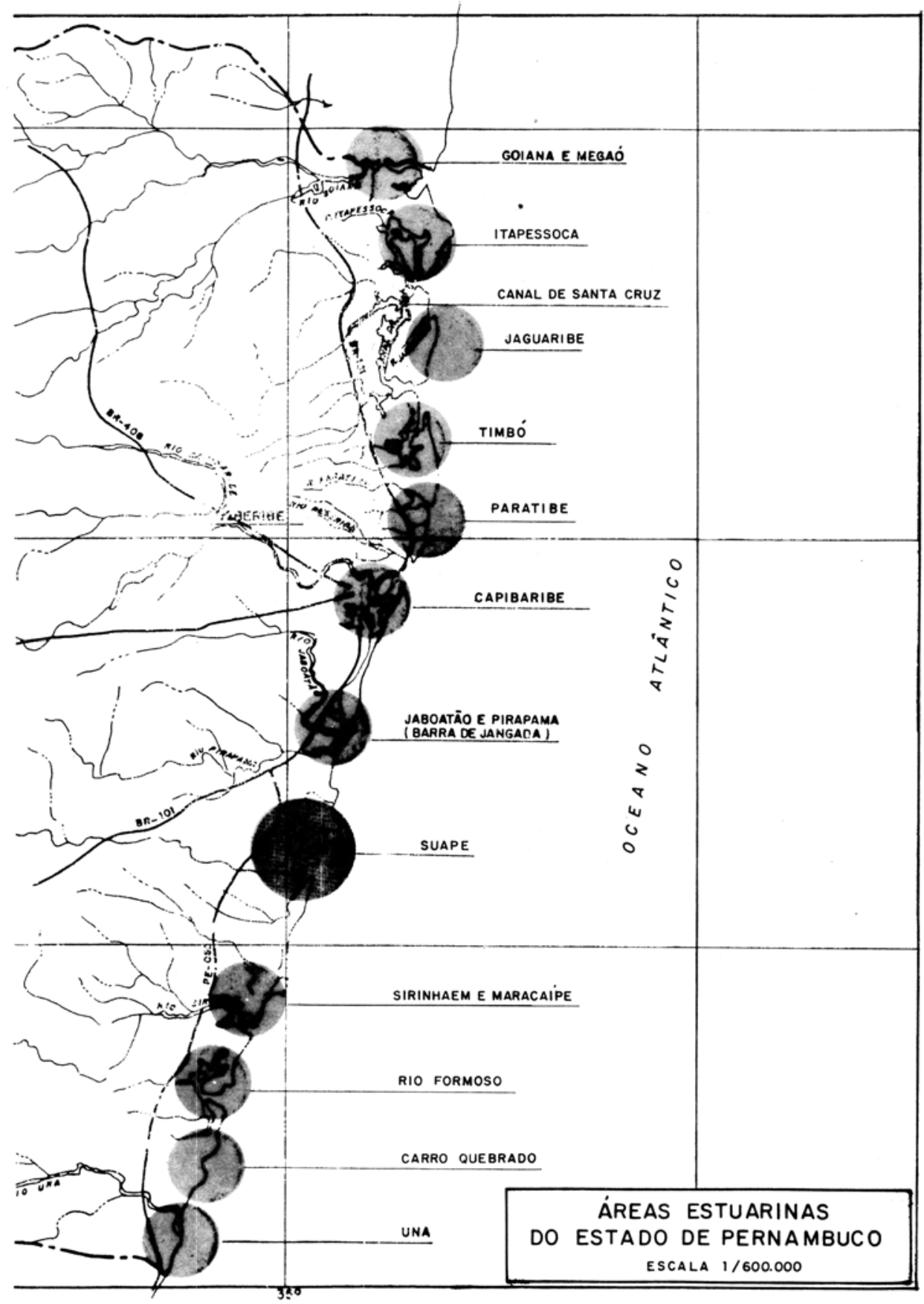

Figura 1 - Indicaçào das treze zonas estuarinas, ao longo do litoral de Pernambuco 


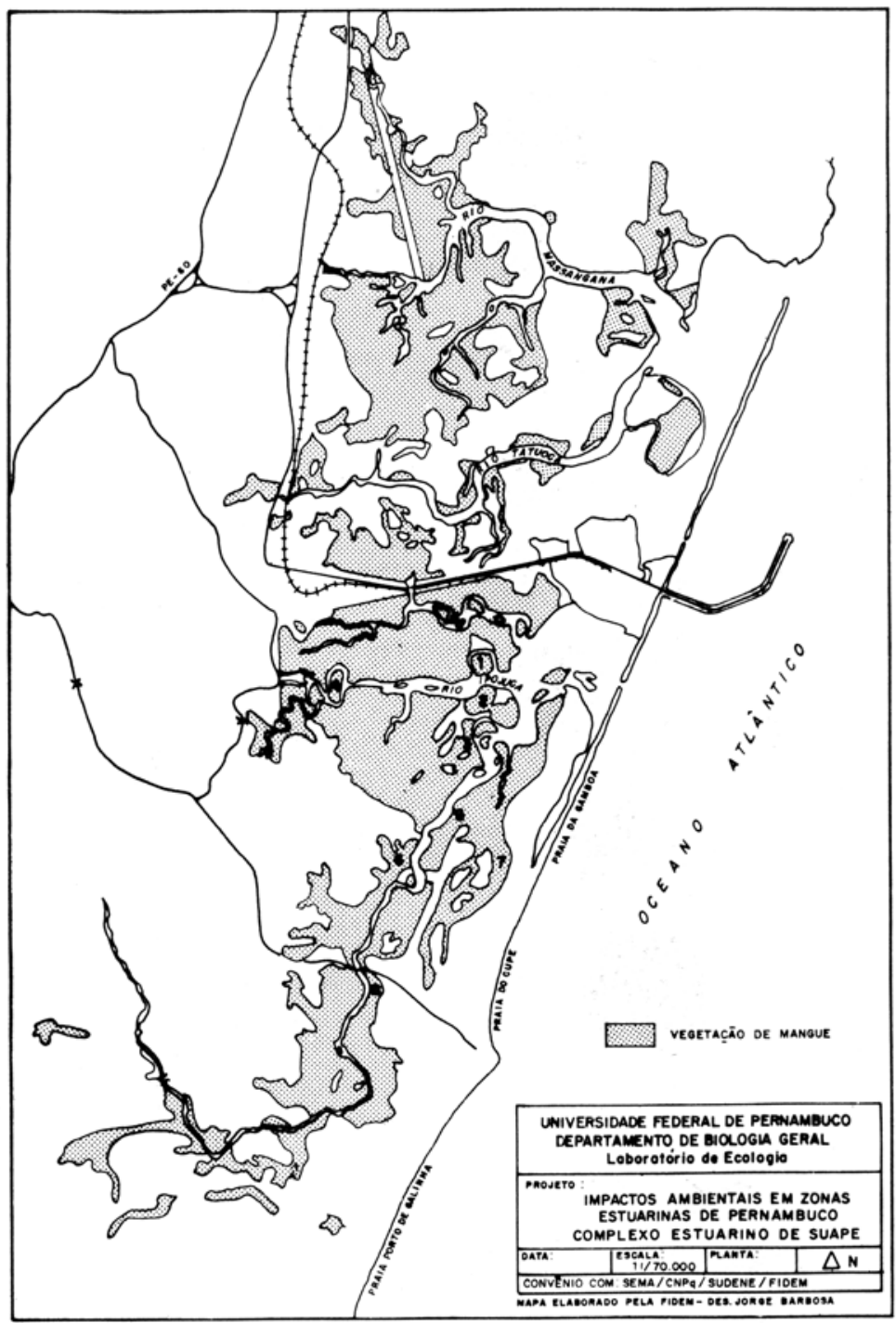

Figura 2 - Mapa da região de Suape em 1988 com a localização das oito estaçōes de amostragem, para caracterização da estrutura do manguezal. 


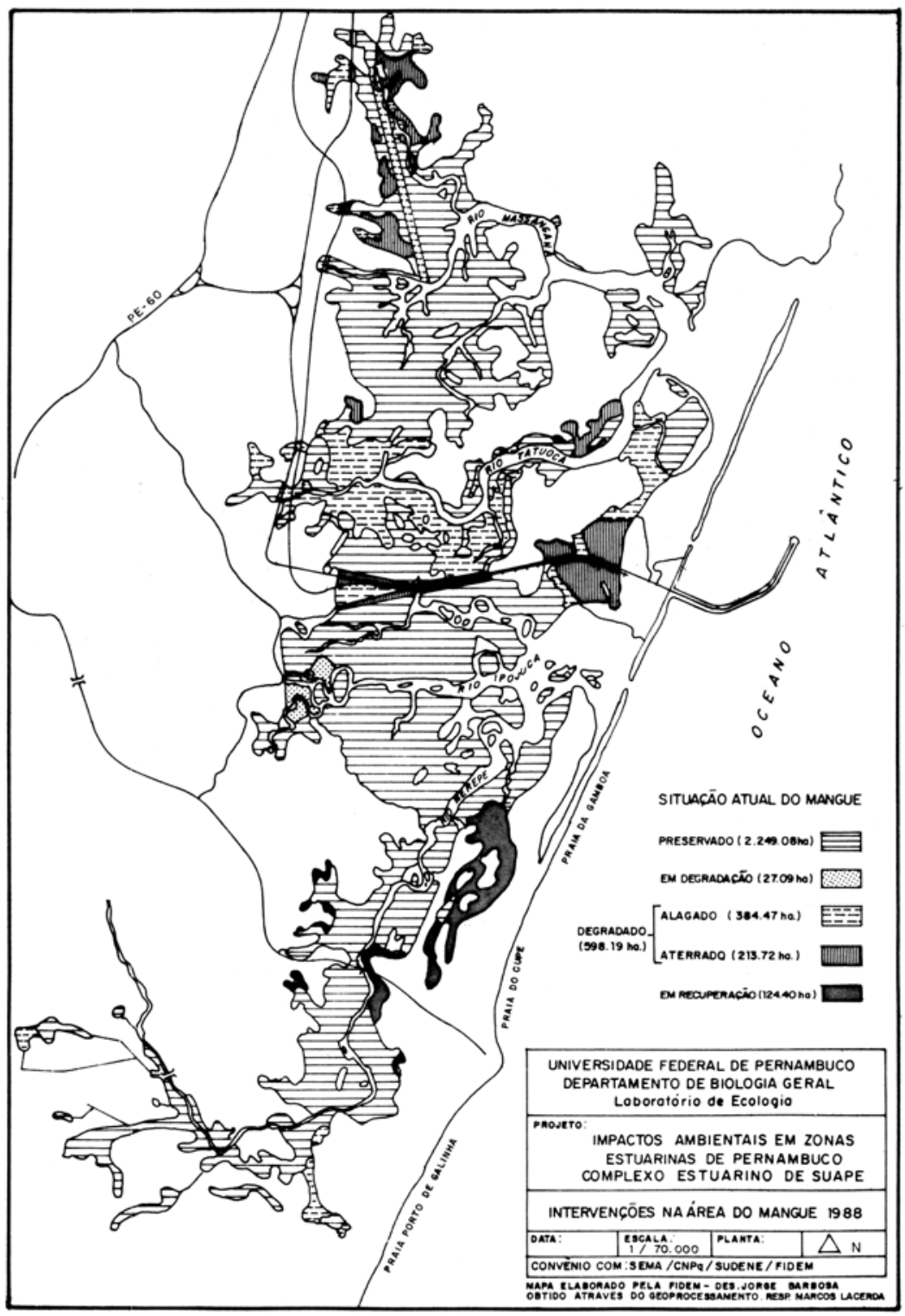



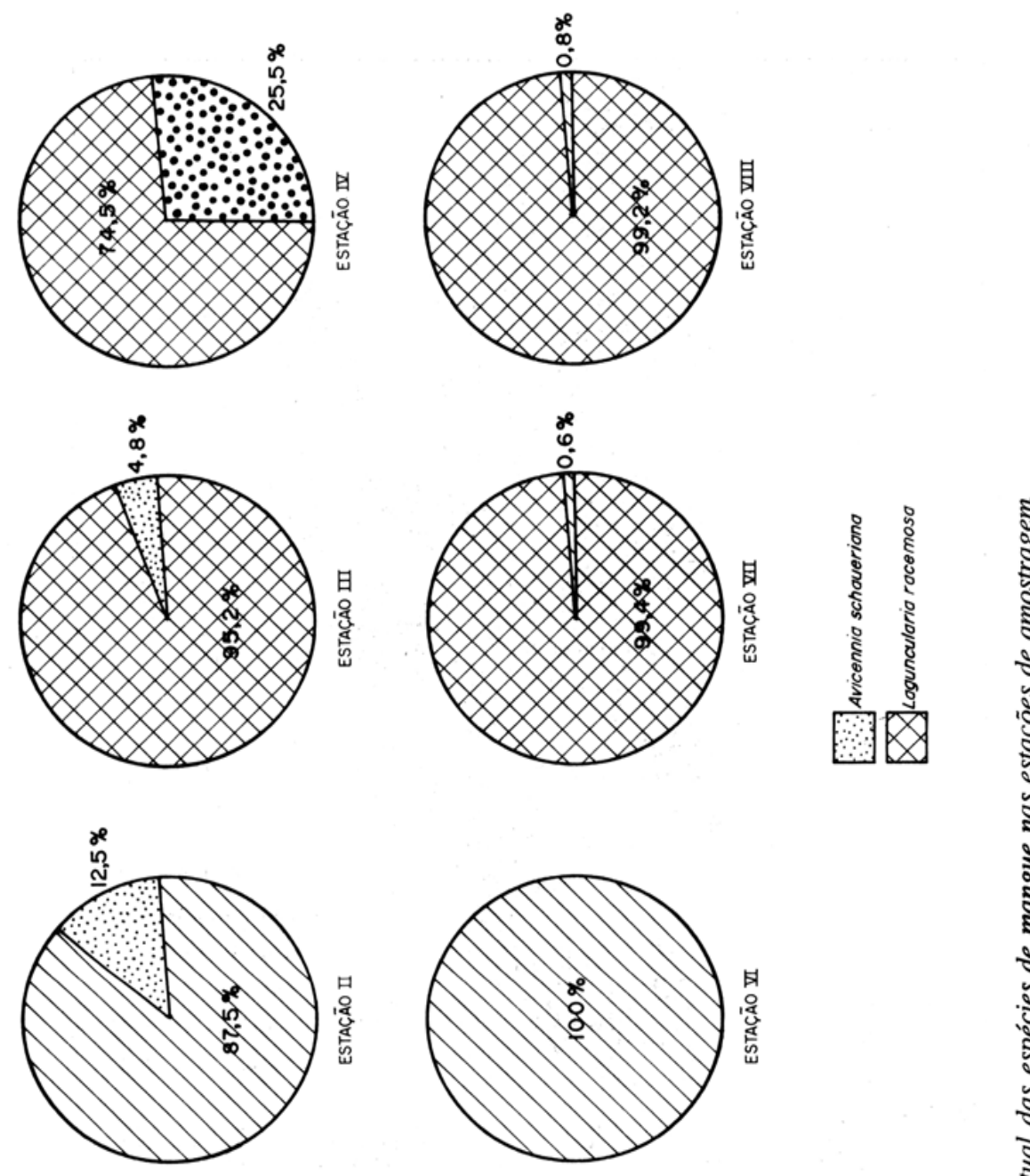

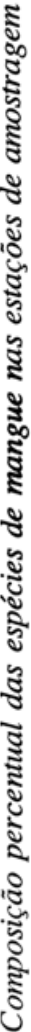
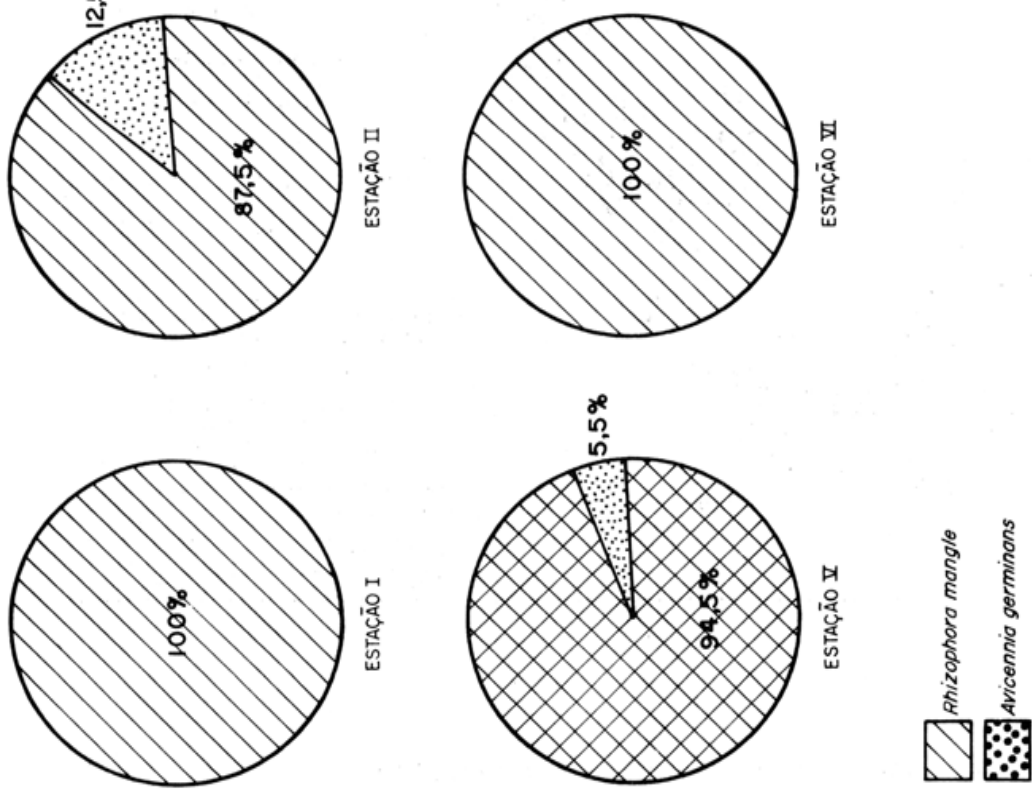

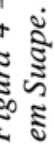



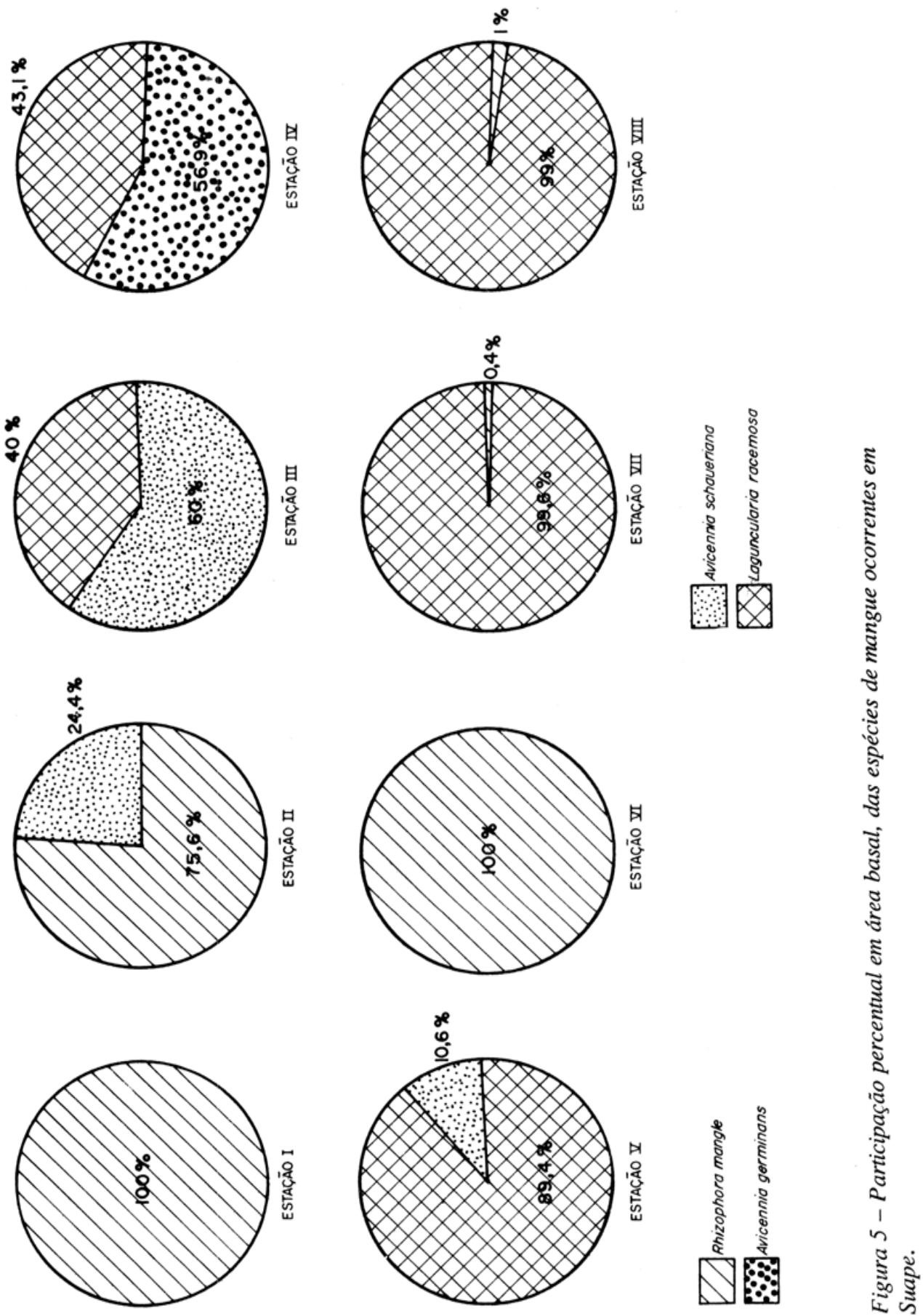